\title{
Endobronchial Tumors Presenting as Asthma
}

\author{
Ahmet Arısoy MD, Selami Ekin MD, Hulya Gunbatar MD, Bunyamin Sertogullarından MD, \\ Huseyin Akdeniz MD, Gulay Bulut MD, Hanifi Yildiz MD, Remzi Erten MD, and \\ Hilmi Demirkiran MD
}

\section{Introduction}

Primary tracheobronchial tumors are rare neoplasms. They frequently develop in the trachea, carina, and endobronchial regions. ${ }^{1}$ Because they are rare and because of the variation in their histogenesis, chest $\mathrm{x}$-ray findings and clinical and operational outcomes have not been well elucidated. ${ }^{2,3}$ Endobronchial tumors may be benign or show low- or high-grade malignancy.4-6 Affected patients generally present with symptoms of either asthma or infection that has developed as a result of obstruction..$^{2,4,6}$ However, these symptoms are nonspecific. We herein report 4 such affected subjects in our clinic and discuss their symptoms, pathological findings, and treatments.

\section{Case Summary}

\section{Case 1}

A 31-y-old female subject had been treated for asthma for $5 \mathrm{y}$. Although she was using high doses of inhaled steroids, $\beta$ mimetics, montelukast, and theophylline, her symptoms continued. Physical examination revealed decreased breath sounds on the left side. Thoracic computed tomography (CT) was performed to follow up the ob-

\footnotetext{
Drs Arisoy is affiliated with the Pulmonary Medicine Department, Dr Akdeniz is affiliated with the Radiology Department, and Dr Demirkiran is affiliated with the Anesthesiology and Reanimation Department, Private Istanbul Hospital, Istanbul, Turkey. Drs Ekin, Gunbatar and Sertogullarından are affiliated with the Pulmonary Medicine Department, and Drs Bulut and Erten are affiliated with the Pathology Department, Yüzüncü Yıl University, Van, Turkey. Dr Yildiz is affiliated with the Pulmonary Medicine Department, Private Lokman Hekim Hospital, Van, Turkey.
}

The authors have disclosed no conflicts of interest.

Correspondence: Ahmet Arısoy, Pulmonary Medicine Department, Private Istanbul Hospital, 65100 Istanbul, Turkey. E-mail: drahmetarisoy@ gmail.com.

DOI: $10.4187 /$ respcare. 02871 served radiolucency in the left lung on her chest x-ray. Endobronchial narrowing of the left main bronchus and resultant air trapping were found on thoracic CT. Rigid bronchoscopy revealed a lesion completely occluding the left main bronchus. A biopsy was performed, and the pathological findings revealed an adenoid cystic carcinoma (Fig. 1). She was treated with open surgery. Her symptoms and physical examination findings improved after surgery. We discontinued asthma treatment.

\section{Case 2}

A 23-y-old male subject with a 5-pack-year cigarette history had been treated for asthma for $4 \mathrm{y}$. He was using asthma medications irregularly. Physical examination revealed bilateral rhonchi. His chest x-ray was normal. Thorax CT revealed an endobronchial lesion in the right main bronchus, and follow-up bronchoscopy revealed a pedunculated, hemorrhage-prone mass lesion almost completely occluding the right main bronchus. A biopsy revealed a typical carcinoid tumor (Figs. 2 and 3). He was treated with interventional bronchoscopy with electrocautery.

\section{Case 3}

A 55-y-old male subject had been treated for asthma for $2 \mathrm{y}$. Although he was using high doses of inhaled steroids, $\beta$ mimetics, and montelukast, his symptoms continued. Physical examination revealed decreased breath sounds on the right side. Chest $\mathrm{x}$-ray revealed right hilar enlargement, and thoracic CT showed an $\sim 2-\mathrm{cm}$ lesion in his right main bronchus. Bronchoscopy showed two mass lesions almost completely occluding the right main bronchus. The biopsy result revealed adenoid cystic carcinoma (Fig. 4). He was treated with open surgery.

\section{Case 4}

A 30-y-old female subject had been treated for asthma for $4 \mathrm{y}$. Her symptoms continued despite her regular use of asthma medications. Her chest X-ray was normal. Thoracic 


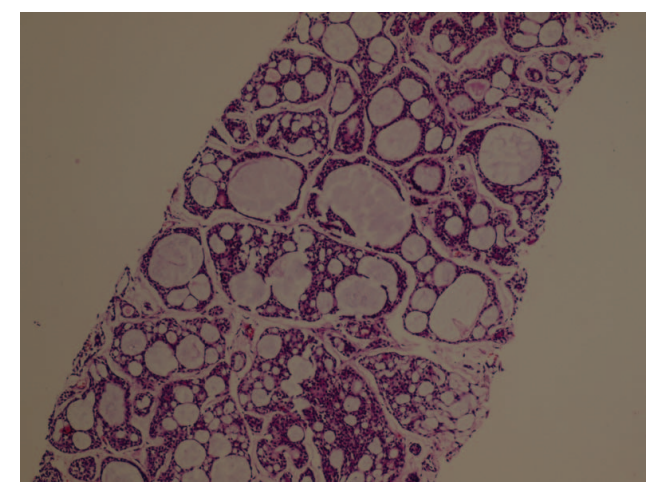

Fig. 1. Case 1: histopathological image of adenoid cystic carcinoma of the lung (hematoxylin and eosin stain, magnification $\times 100)$.

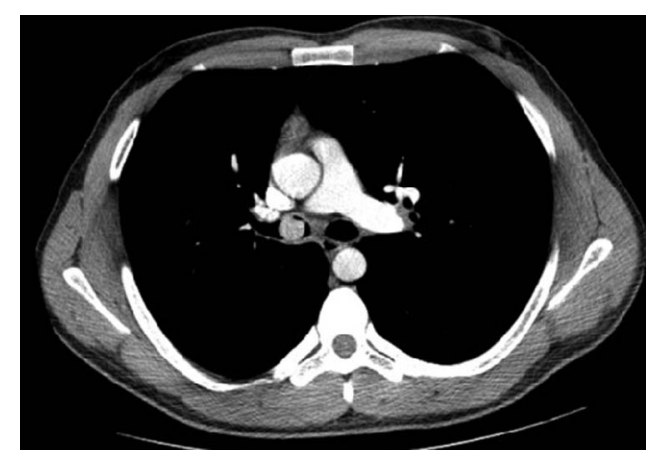

Fig. 2. Case 2: mass lesion almost entirely blocking the right main bronchus.

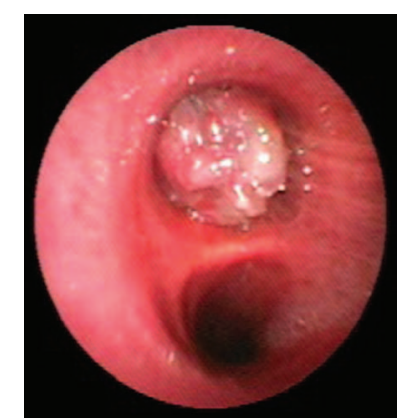

Fig. 3. Case 2: bronchoscopic finding of pedunculated mass lesion almost entirely blocking the right main bronchus.

CT revealed an endobronchial lesion in the right main bronchus that did not entirely occlude the lumen. The pathological result was adenoid cystic carcinoma. She was treated with open surgery.

\section{Discussion}

Clinically, endobronchial tumors cause air trapping or secondary lung infections. ${ }^{2-6}$ Their diagnosis is usually delayed because they do not appear on chest X-rays. CT

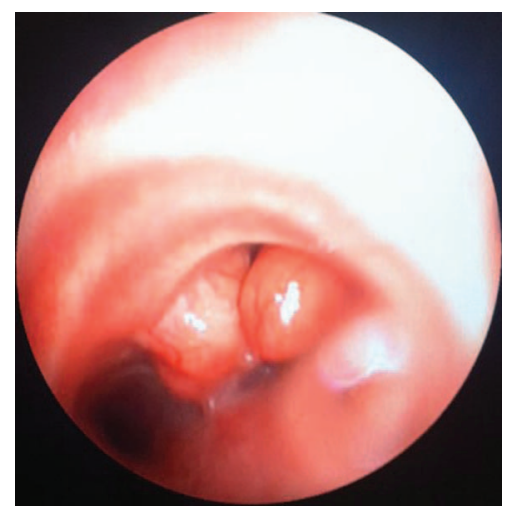

Fig. 4. Case 3: 2 mass lesions blocking the right main bronchus.

and bronchoscopy are helpful in obtaining a diagnosis in these cases. ${ }^{4}$ In affected patients, interventional bronchoscopy is critical for timely treatment and diagnosis. All of our subjects were being treated for asthma but did not respond adequately to treatment. None of our subjects presented with secondary infection.

Tracheobronchial tumors may be benign or show lowor high-grade malignancy. Therefore, CT is useful in revealing lesions not expected to be associated with these tumors. Solitary papillomas, mucous tissue adenomas, inflammatory myofibroblastic tumors, schwannomas, leiomyomas, hamartomas, hemangiomas, and chondromas from benign tumors have been reported. . $^{3,4-10}$

Squamous cell cancer of the tracheobronchial tree, carcinoid tumors, adenoid cystic carcinomas, and mucoepidermoid carcinomas from low-grade malignant tumors have also been reported. ${ }^{2-4,6,11,12}$ These tumors are low grade but can recur after treatment or can result in distant metastasis. Three of our subjects had adenoid cystic carcinomas, and one had a carcinoid tumor. CT revealed no lymph node metastasis or distant metastasis in any subject. Because our subjects were identified in 2012 and 2013, we believe that it is too early to evaluate them for recurrence; however, recurrence has not been observed in the 4 subjects to date.

Most of the 14 subjects with endobronchial and adenoid cystic carcinomas examined by Albers et $\mathrm{al}^{13}$ had nonspecific breathing complaints such as cough and dyspnea due to narrowing of the airways; however, few subjects had asthma anamnesis with long-term wheezing and stridor complaints. Nine of these subjects were female, and 5 were male. Of our subjects, 2 were female, and 2 were male.

Dewan et $\mathrm{al}^{14}$ reported that the right side was most frequently affected in 31 subjects with tracheobronchial carcinoid tumors. The tumor was present in a main bronchus in 30 of these 31 subjects; one patient had a tracheal tumor. Most of these subjects had typical carcinoid tumors. In our subject with a carcinoid tumor, the tumor was 
located at the entrance of the right main bronchus, and its pathology was consistent with a typical carcinoid tumor.

Moran et al ${ }^{15}$ reported that 11 of 16 subjects with adenoid cystic carcinoma were male, and 5 were female. Of these subjects, 7 underwent pneumonectomy, 6 underwent lobectomy, and 2 underwent lobectomy and chemotherapy. One subject underwent only chemotherapy because of disease progression. For our subjects, mass excision only during open surgery was performed in cases 1-3 with no resection. Case 2 also underwent interventional bronchoscopy with electrocautery. The symptoms and physical examination findings of all of our subjects improved after intervention.

In conclusion, tracheobronchial tumors, endobronchial adenoid cystic carcinomas, and carcinoid tumors should be suspected in patients with chronic coughing or frequent lung infections who undergo long-term treatment for asthma and who do not respond well to asthma medications. Even if the chest x-ray findings are normal, thoracic CT and, if necessary, bronchoscopy should be performed.

\section{Teaching Points}

- Chest CT, as well as bronchoscopy, should be performed in treatment-resistant patients with asthma, even in those with a normal chest x-ray.

- Endobronchial tumors should be suspected in patients with chronic coughing or frequent lung infections who undergo long-term treatment for asthma.

\section{REFERENCES}

1. Takeda S, Hashimoto T, Kusu T, Kawamura T, Nojiri T, Funakoshi $\mathrm{Y}$, et al. Management and surgical resection for tracheobronchial tumors institutional experience with 12 patients. Interact Cardiovasc Thorac Surg 2007;6(4):484-489.
2. Pearson FG, Todd TR, Cooper JD. Experience with primary neoplasms of the trachea and carina. J Thorac Cardiovasc Surg 1984; 88(4):511-518.

3. Xu LT, Sun ZF, Li ZJ, Wu LH, Wang ZZ. Tracheobronchial tumors: an eighteen-year series from Capital Hospital, Peking, China. Ann Thorac Surg 1983;35(6):590-596.

4. Aberle DR, Brown K, Young DA, Batra P, Steckel RJ. Imaging techniques in the evaluation of tracheobronchial neoplasms. Chest 1991;99(1):211-215.

5. Schneider P, Schirren J, Muley T, Vogt-Moykopf I. Primary tracheal tumors: experience with 14 resected patients. Eur J Cardiothorac Surg 2001;20(1):12-18.

6. Refaely Y, Weissberg D. Surgical management of tracheal tumors. Ann Thorac Surg 1997;64(5):1429-1432; discussion 1432-1433.

7. Lam CW, Talbot AR, Yeh KT, Lin SC, Hsieh CE, Fang HY. Human papillomavirus and squamous cell carcinoma in a solitary tracheal papilloma. Ann Thorac Surg 2004;77(6):2201-2202.

8. Hsu HS, Wang CY, Li WY, Huang MH. Endotracheobronchial neurofibroma. Ann Thorac Surg 2002;74(5):1704-1706.

9. Rusch VW, Schmidt RA. Tracheal schwannoma: management by endoscopic laser resection. Thorax 1994;49(1):85-86.

10. Shah H, Garbe L, Nussbaum E, Dumon JF, Chiodera PL, Cavaliere $\mathrm{S}$. Benign tumors of the tracheobronchial tree. Endoscopic characteristics and role of laser resection. Chest 1995;107(6):1744-1751.

11. Breyer RH, Dainauskas JR, Jensik RJ, Faber LP. Mucoepidermoid carcinoma of the trachea and bronchus: the case for conservative resection. Ann Thorac Surg 1980;29(3):197-204.

12. Conlan AA, Payne WS, Woolner LB, Sanderson DR. Adenoid cystic carcinoma (cylindroma) and mucoepidermoid carcinoma of the bronchus. Factors affecting survival. J Thorac Cardiovasc Surg 1978; 76(3):369-377.

13. Albers E, Lawrie T, Harrell JH, Yi ES. Tracheobronchial adenoid cystic carcinoma: a clinicopathologic study of 14 cases. Chest 2004; 125(3):1160-1165.

14. Dewan RK, Kesieme EB, Ramchandani R. Surgical treatment for tracheobronchial carcinoid tumors: a 16-year experience. Asian Cardiovasc Thorac Ann 2012;20(1):53-57.

15. Moran CA, Suster S, Koss MN. Primary adenoid cystic carcinoma of the lung. A clinicopathologic and immunohistochemical study of 16 cases. Cancer 1994;73(5):1390-1397. 